\title{
FATWA DSN MUI NOMOR 86/DSN-MUI/XII/2012 TENTANG HADIAH DALAM PENGHIMPUNAN DANA LEMBAGA KEUANGAN SYARIAH: IMPLEMENTASI PADA BMT UGT SIDOGIRI PASURUAN1)
}

\author{
Khoirun Nisak \\ Program Studi S1 Ekonomi Islam-Fakultas Ekonomi dan Bisnis-Universitas Airlangga \\ Email: khoirun.nisak-12@feb.unair.ac.id \\ Irham Zaki \\ Departemen Ekonomi Syariah-Fakultas Ekonomi dan Bisnis-Universitas Airlangga \\ Email: irham.zaki@feb.unair.ac.id
}

\begin{abstract}
:
This research aimed to analyze the implementation process of the indonesian council of ulama (DSN MUI) regulation number 86/DSN-MUI/XII/2012 on the prize fund of Islamic financial insitutions in the Baitul Maal Wat Tamwil (BMT) UGT Sidogiri Pasuruan. The method used in this research is qualitative approach using case study strategy in BMT UGT Sidogiri Pasuruan. The data collection was done by interview and documentation. The validation technique used is triangulation technique of sources. The analysis techniques in this research uses Miles and Huberman Theory.

The results of this research based on the indonesian council of ulama (DSN MUI) regulation number 86/DSN-MUI/XII/2012 on the prize fund of Islamic financial insitutions. Based $n$ the analysis done by researches, BMT UGT Sidogiri Pasuruan has not been effective yet in applying regulation issued by DSN MUI, especially on the regulation number 86/DSNMUI/XII/2012, at the ban point of making prize program as a habit
\end{abstract}

Keywords: BMT, Prize Fund, DSN MUI Regulation, Islamic Financial Institution.

\section{PENDAHULUAN}

\section{Latar Belakang}

Al-Quran dan hadits merupakan

suatu pedoman dalam menjalankan ibadah dan amaliyah seorang muslim. Keduanya memiliki porsi paling utama yang menjadi pedoman dalam menetapkan hukum Islam. Dalam menetapkan suatu hukum para mujtahid (orang yang melakukan ijtihad) tetap berpedoman pada Al-Quran dan hadits Rasulullah.

Firman Allah dalam salah satu ayat Al-Quran (An-Nisa ayat 58 )

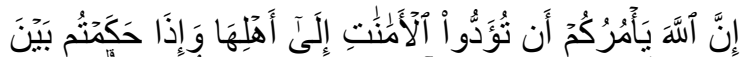

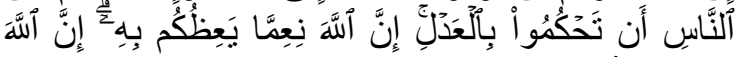

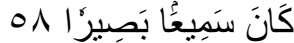

Artinya: Sungguh, Allah menyuruhmu menyampaikan amanat kepada yang berhak menerimanya, dan apabila kamu menetapkan hukum di antara manusia hendaknya kamu menetapkannnya dengan adil. Sungguh Allah sebaikbaiknya yang memberikan pengajaran kepadamu. Sungguh, Allah Maha Pendengar, Maha Melihat (Q.S An-Nisa: 58) (Depag, 2005:87) Semakin bertambahnya kebutuhan hidup seseorang dapat menimbulkan sebuah persaingan baru dalam dunia usaha. Semakin banyak persaingan maka sebuah perusahaan tentu mempunyai berbagai strategi khusus dalam menghadapi persaingan tersebut. Dalam Islam persaingan diperbolehkan bahkan dianjurkan. Namun, persaingan yang diperbolehkan oleh Islam adalah persaingan dalam kebaikan seperti persaingan dalam usaha.

Lembaga keuangan syariah merupakan lembaga keuangan yang baru berkembang di Indonesia namun perkembangannya bisa dikatakan cukup

1 Jurnal ini merupakan bagian dari skripsi dari Khoirun Nisak, NIM: 041211433001, yang diuji pada 09 Agustus 2016 
Nisak, et al/Jurnal Ekonomi Syariah Teori dan Terapan Vol. 4 No. 5 Mei 2017: 353-366; FATWA DSN MUI NOMOR 86/DSN-MUI/XII/2012 TENTANG HADIAH DALAM PENGHIMPUNAN DANA LEMBAGA KEUANGAN SYARIAH: IMPLEMENTASI PADA BMT UGT SIDOGIRI PASURUAN

pesat. Data OJK menunjukkan bahwa sampai April 2016 jumlah industri keuangan non bank syariah sejumlah 90 unit (www.ojk.go.id).

Sebagai lembaga keuangan yang orientasinya adalah profit maka dibutuhkan untuk mempertahankan profit yang didapatkan ataupun ingin menjadikan profit yang didapatkan melebihi biasanya. Dalam perkembangannya menghadapi persaingan banyak dari beberapa lembaga keuangan memiliki strategi dengan memberikan hadiah pada masyarakat agar tetap menjadi nasabah ataupun menarik perhatian nasabah baru.

sebuah hadits yang memiliki arti sebagai berikut :

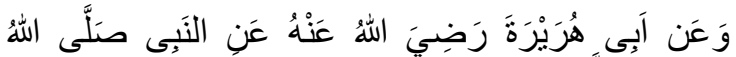

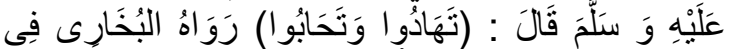

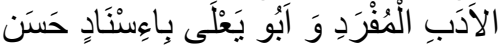

Artinya: Dari Abu Hurairah r.a. dari Nabi Muhammad SAW bersabda : "saling memberi hadiahlah kamu sekalian, niscaya kalian akan saling mencintai". (Diriwayatkan oleh Al-Bukhari dalam AlAdabul Mufrad dan Abu Ya'la dengan sanad yang hasan) (Al- Hafizh Ibnu Hajar al- Ashaalani, 2012:252).

Dalam Fatwa MUI program berhadiah diperbolehkan dengan menggunakan beberapa ketentuan yang telah ditentukan oleh MUI melalui peraturan DSN MUI No 86 tentang hadiah dalam penghimpunan dana lembaga keuangan syariah. Ketentuan yang harus dipatuhi oleh lembaga keuangan syariah adalah :

1. Hadiah yang diberikan tidak boleh berupa vang, harus berupa barang.
2. Hadiah tersebut milik lembaga keuangan tersebut.

3. Dalam akad wadiah hadiah tidak boleh diperjanjikan di awal.

4. Lembaga keuangan syariah boleh menentukan syarat kepada penerima hadiah.

5. Hadiah yang diberikan tidak boleh mengandung risywah atau suap dan berpotensi pada praktek Maisir, Riba, dan Gharar.

Baitul Maal wat Tamwil (BMT) sebagai lembaga keuangan mikro syariah memiliki beberapa keunggulan dibandingkan perbankan syariah. Salah satu BMT yang menerapkan inovasi untuk menarik minat nasabah dengan menggunakan program berhadiah adalah BMT UGT Sidogiri. BMT UGT Sidogiri merupakan salah satu BMT yang mengalami pertumbuhan yang pesat dibuktikan pada tahun 2015 BMT UGT Sidogiri menempati posisi keenam dari seratus BMT terbesar di Indonesia.

Hadiah merupakan salah satu cara untuk sebuah BMT dapat mempertahankan kinerjanya dengan menghimpun dana dari nasabah lama maupun calon nasabah agar dana di BMT tersebut dapat digunakan operasional BMT. dalam fatwa DSN MUI nomor 86/XII/DSNMUI/2012 diperbolehkan memberikan hadiah dengan menggunakan cara qur'ah atau pengundian. Diperbolehkannya pengundian dalam Islam tersebut dengan catatan tidak boleh melanggar aturan 
Nisak, et al/Jurnal Ekonomi Syariah Teori dan Terapan Vol. 4 No. 5 Mei 2017: 353-366; FATWA DSN MUI NOMOR 86/DSN-MUI/XII/2012 TENTANG HADIAH DALAM PENGHIMPUNAN DANA LEMBAGA KEUANGAN SYARIAH: IMPLEMENTASI PADA BMT UGT SIDOGIRI PASURUAN

syariat Islam seperti adanya praktek judi atau maisir dalam praktek pengundian. Dalam prakteknya di BMT Sidogiri menggunakan cara tersebut untuk memberikan hadiah kepada nasabahnya. Berdasarkan pemaparan di atas, penulis mengangkat tema jurnal ini dengan judul "IMPLEMENTASI FATWA NOMOR 86/DSN-MUI/XII/2012 TENTANG HADIAH DALAM PENGHIMPUNAN DANA LEMBAGA KEUANGAN SYARIAH PADA BMT (Baitul Maal Wat Tamwil) Sidogiri Pasuruan".

Berdasarkan Uraian latar belakang yang ada maka permasalahan penelitian ini dapat dirumuskan sebagai berikut: bagaimana penerapan fatwa DSN MUI Nomor 86/DSN-MUI/XII/2012 tentang hadiah dalam Penghimpunan Dana Lembaga Kevangan Syariah di BMT UGT Sidogiri Pasuruan? Adapun tujuan dari penelitian ini adalah untuk mengetahui praktek pemberian hadiah dalam penghimpunan dana yang terjadi di Baitul Maal Wat Tamwil (BMT) UGT Sidogiri Pasuruan dengan menggunakan penerapan fatwa DSN Nomor 86/DSNMUI/XII/2012 tentang hadiah dalam Penghimpunan Dana Lembaga Kevangan Syariah.

\section{LANDASAN TEORI}

Abdul Aziz Muhammad Azzam dalam bukunya "Figh Muamalah; Sistem Transaksi dalam Islam" (2010) bahwa hibah, pemberian ('athiyah) dan sedekah maknanya sangat berdekatan. Semua berupa pemberian atas hak milik seseorang sewaktu masih hidup tanpa ada ganti. Karena penyebutan nama pemberian ('athiyah) mencakup semuanya baik sedekah (zakat), dan hadiah. Hadiah merupakan bagian dari hibah, sedekah dan athiyah karena masing-masing memiliki persamaan dan berbedaan pada substansinya.

sebuah hadits yang diriwaayatkan Imam Bukhari menyatakan bahwasanya Rasulullah SAW menganjurkan umatnya untuk saling memberi hadiah. seperti yang diriwayatkan Abu Hurairah ra.:

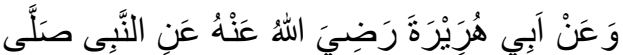

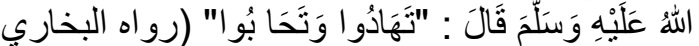

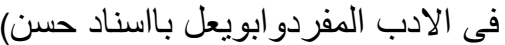

Artinya : Dari Abu Hurairah r.a. dari Nabi saw. Beliau bersabda: "Saling memberi hadiahlah kamu sekalian, niscaya kalian akan saling mencintai. "

Ahmad Warson Munawwir dalam Matsna (2014) menjelaskan secara etimologi fatwa berasal dari bahasa Arab yaitu (الإفتاء) yang merupakan mufrod (tunggal) dan memiliki arti pendapat resmi atau fatwa. Mardhani dalam matsna menyebutkan hakikat dan ciri-ciri berfatwa yaitu :

a. Usaha memberikan penjelasan;

b. Penjelasan yang diberikan itu adalah tentang hukum syara' yang diperoleh melalui hasil ijitihad;

c. Yang memberikan penjelasan adalah orang yang ahli dalam bidang yang dijelaskannya itu;

d. Penjelasan diberikan kepada orang yang bertanya yang belum mengetahui hukumnya. 
Nisak, et al/Jurnal Ekonomi Syariah Teori dan Terapan Vol. 4 No. 5 Mei 2017: 353-366; FATWA DSN MUI NOMOR 86/DSN-MUI/XII/2012 TENTANG HADIAH DALAM PENGHIMPUNAN DANA LEMBAGA KEUANGAN SYARIAH: IMPLEMENTASI PADA BMT UGT SIDOGIRI PASURUAN

Para ulama' dalam menetapkan hukum syara' adalah melalui dalil-dalil dan sumber hukum sesuai apa yang diperselisihkan dan mengelompokkannya menjadi beberapa metode dan sumber hukum

Berbeda dengan sumber dana dari lembaga keuangan syariah. Bagi lembaga kevangan syariah ada tiga macam sumber dana, yakni modal, titipan, dan investasi (Antonio, 2001:146). Sumber dana tersebut didapatkan dari beberapa produk penghimpunan dana seperti produk titpan dan investasi. Berikut merupakan rincian produk dari penghimpunan dana:

1. Modal

2. Titipan (wadi'ah)

3. Investasi

BMT merupakan salah satu lembaga keuangan syariah. Baitul Maal Wa Tamwil (BMT) pada dasarnya merupakan pengembangan dari konsep ekonomi dalam Islam terutama dalam bidang keuangan. Menurut Widodo, dkk (1999) dalam Hamidah (2007: 16) istilah BMT adalah penggabungan dari Baitul Mal dan Baitul Tamwil. Baitul Maal adalah lembaga keuangan yang kegiatannya mengelola dana yang bersifat nirlaba (sosial).

Didirikannya BMT bertujuan untuk meningkatkan kualitas usaha ekonomi untuk kesejahteraan anggota pada khususnya dan masyarakat pada umumnya agar dapat mandiri dan tidak tergantung pada BMT dengan memberikan modal pinjaman. Namun demikian BMT harus menciptakan suasana keterbukaan, sehingga dapat mendeteksi berbagai kemungkinan yang timbul dari pembiayaan.

\section{METODE PENELITIAN}

Penelitian ini menggunakan pendekatan kualitatif, pendekatan kualitatif adalah pendekatan dengan menggunakan data yang berupa kalimat tertulis atau lisan, peristiwa-peristiwa, pengetahuan, atau proyek studi yang bersifat deskriptif (Nazir, 2003:54). Penelitian ini bertujuan untuk menjawab rumusan masalah yakni bagaimana praktek pemberian hadiah dalam penghimpunan dana di BMT UGT Sidogiri Pasuruan.

Metode yang digunakan untuk meneliti pada penelitian ini adalah studi kasus deskriptif. Cara pengambilan data informan dengan cara purposive sampling. Yin (1996:1) menjelaskan, secara umum studi kasus merupakan strategi yang cocok dalam penelitian jika pokok pertanyaan suatu penelitian berkenaan dengan how atau why.

Ruang lingkup penelitian adalah terkait dengan rumusan masalah mengenai Bagaimana penerapan fatwa DSN Nomor 86/DSNMUI/XII/2012 tentang hadiah dalam Penghimpunan Dana Lembaga Kevangan Syariah di BMT UGT Sidogiri Pasuruan. Jenis dan sumber data penelitian merupakan salah satu faktor yang menjadi pertimbangan dalam penentuan metode pengumpulan data. 
Nisak, et al/Jurnal Ekonomi Syariah Teori dan Terapan Vol. 4 No. 5 Mei 2017: 353-366; FATWA DSN MUI NOMOR 86/DSN-MUI/XII/2012 TENTANG HADIAH DALAM PENGHIMPUNAN DANA LEMBAGA KEUANGAN SYARIAH: IMPLEMENTASI PADA BMT UGT SIDOGIRI PASURUAN

Dalam prakteknya, penelitian ini menggunakan jenis dan sumber data yang berasal dari dua sumber yakni data primer dan sekunder.

Emzir (2012:129) dalam bukunya menjelaskan tentang teknik analisis data dalam penelitian kualitatif menggunakan model Miles dan Huberman. Miles dan Huberman menjelaskan ada tiga kegiatan dalam melakukan analisis data kualitatif. Pertama melakukan reduksi data, reduksi data merupakan proses pemilihan, pemokusan, penyederhanaan, abstraksi, dan pentransformasian "data mentah" yang terjadi dalam catatan-catatan laporan tertulis, reduksi data dilakukan secara terus-menerus sampai laporan akhir lengkap. Kegiatan kedua menurut Miles dan Huberman dalam buku yang ditulis oleh Emzir adalah model data. Model merupakan suatu kumpulan informasi yang tersusun yang membolehkan pendeskripsian kesimpulan dan pengambilan tindakan. Langkah ketiga adalah penarikan dan verifikasi kesimpulan (Emzir, 2012: 133). Dari permulaan pengumpulan data, peneliti kualitatif mulai memutuskan makna sesuatu, mencatat keteraturan, pola-pola, penjelasan, konfigurasi yang mungkin, alur klausal, dan proposisi-proposisi. Namun, untuk mendapatkan kesimpulan masih jauh dan masih samar. Verifikasi kesimpulan merupakan makna yang muncul dari data yang telah teruji kepercayaannya.

\section{HASIL DAN PEMBAHASAN}

Pokok pembahasan dalam penelitian ini ada tiga:

\section{a. Ketentuan terkait hadiah.}

Fatwa DSN MUI nomor 86/DSNMUI/XII-/2012 tentang hadiah dalam penghimpunan dana lembaga keuangan syariah memberikan ketentuan hadiah yang diberikan kepada nasabah atau anggotanya. Ketentuan tersebut berupa barang yang diberikan, dana untuk hadiah, dan syarat yang harus dipenuhi oleh nasabah atau anggota. Ketentuan barang yang diberikan diantaranya adalah adanya larangan hadiah berupa uang, hadiah harus berupa benda yang berwujud, benda yang halal, harus milik LKS.

Baitul Maal wat Tamwil (BMT) UGT Sidogiri Pasuruan memberikan hadiah kepada anggotanya berupa barang elektronik rumah tangga sebagai doorprize dan sebagai hadiah utamanya adalah motor, umroh, dan mobil. Hadiah tersebut didapat dari dana yang didapatkan dari pos BMT UGT Sidogiri. Pos BMT UGT merupakan dana yang didapatkan dari bagi hasil yang didapatkan dari akad-akad yang ada di BMT UGT. Barang hadiah tersebut merupakan barang milik BMT bukan milik pihak lain.

Ketentuan terkait hadiah yang lainnya adalah dana yang dipakai untuk mendapatkan hadiah yang diberikan kepada anggota. Dalam menjamin bahwasanya barang yang diberikan kepada anggota merupakan milik sendiri 
Nisak, et al/Jurnal Ekonomi Syariah Teori dan Terapan Vol. 4 No. 5 Mei 2017: 353-366; FATWA DSN MUI NOMOR 86/DSN-MUI/XII/2012 TENTANG HADIAH DALAM PENGHIMPUNAN DANA LEMBAGA KEUANGAN SYARIAH: IMPLEMENTASI PADA BMT UGT SIDOGIRI PASURUAN

atau milik BMT UGT, pihak BMT memberikan penjelasan tentang dana yang dipakai untuk gebyar hadiah tersebut.

Ketentuan yang selanjutnya adalah tentang syarat yang harus dipenuhi oleh anggota BMT UGT Sidogiri. Dalam membuat persyaratan lembaga keuangan tidak diperbolehkan untuk menjurus kepada praktik riba. Pada praktiknya BMT UGT Sidogiri syarat yang diberikan adalah hanya membuka tabungan mudharabah berjangka minimal satu tahun dan setiap kelipatan lima juta akan mendapatkan satu kupon. Namun, sebelum membuka tabungan mudharabah berjangka anggota harus memiliki tabungan biasa dengan akad mudharabah musytarakah untuk mendapatkan bagi hasil setiap bulannya. Tabungan mudharabah merupakan tabungan yang berlandaskan akad mudharabah musytarakah dengan nisbah bagi hasil yang diperoleh anggota sebesar 50\% dan 50\% untuk BMT UGT Sidogiri.

\section{b. Ketentuan cara penentuan penerima hadiah.}

Fatwa DSN MUI nomor 86/DSNMUI/XII/2012 tentang hadiah dalam penghimpunan dana lembaga keuangan syariah menetapkan hadiah yang diberikan kepada anggota atau nasabah tidak diperbolehkan bersifat menguntungkan pribadi pejabat lembaga keuangan syariah atau adanya suap, terhindar dari maysir, gharar, riba, dan akl al-mal bil bathil, dan pemberian hadiah boleh dilakukan langsung dan melalui pengundian. Dalam praktik hadiah, risywah bisa dilakukan dengan memberikan suap kepada panitia agar seseorang tersebut bisa mendapatkan hadiah. Hal ini yang tidak diperbolehkan dalam memberikan hadiah yang dimaksudkan oleh fatwa DSN MUI nomor 86/DSN-MUI/XII/2012 tentang hadiah dalam penghimpunan dana lembaga keuangan syariah. Hadiah yang diberikan kepada panitia diperbolehkan dengan syarat hadiah tersebut diberikan setelah terjadinya pengundian atau pemberian hadiah, hal ini bukan termasuk suap atau risywah.

BMT UGT Sidogiri merupakan lembaga keuangan syariah yang awal didirikannya bertujuan mensyariahkan ekonomi yang ada di sekitar desa Sidogiri. Sedangkan hadiah merupakan salah satu program yang diadakan oleh BMT UGT Sidogiri yang bertujuan untuk menarik minat anggota baik yang baru maupun yang lama untuk memberikan dana kepada BMT UGT Sidogiri Pasuruan untuk dikelola sesuai dengan sistem syariah. Menurut bapak Bahri selaku kadiv simpan pinjam menjelaskan bahwa tidak mungkin lembaga keuangan yang berlandaskan syariah akan menjalankan sesuatu keluar dari koridor syariah, begitupun dengan melakukan risywah atau suap.

Selanjutnya, yakni ketentuan tentang kewajiban untuk terhindar dari maysir, riba, dan gharar serta akl al-mal bil 
Nisak, et al/Jurnal Ekonomi Syariah Teori dan Terapan Vol. 4 No. 5 Mei 2017: 353-366; FATWA DSN MUI NOMOR 86/DSN-MUI/XII/2012 TENTANG HADIAH DALAM PENGHIMPUNAN DANA LEMBAGA KEUANGAN SYARIAH: IMPLEMENTASI PADA BMT UGT SIDOGIRI PASURUAN

bathil. Maysir merupakan sesuatu yang dilarang oleh Islam yang mana maysir merupakan perjudian. Maysir dalam undian berhadiah dapat terjadi ketika peserta membayar iuran, undian yang seperti ini dilarang sekalipun iurannya dalam jumlah sedikit. Hal yang seperti ini adalah gharar yang nyata, di mana peserta membayar iuran yang kemungkinan ia mendapatkan hadiah sehingga berlaba atau ia tidak mendapat apa-apa sehingga ia rugi, maka undian ini termasuk maysir.

Dalam praktiknya BMT UGT Sidogiri tidak menerapkan iuran pembayaran pendaftaran untuk mendapatkan kupon undian berhadiah. Selain itu, BMT UGT telah menjelaskan hadiah apa saja yang bisa anggota dapatkan.

Selanjutnya yakni ketentuan mengenai tata cara pemberian hadiah. Pemberian hadiah oleh lembaga kevangan syariah bisa dilakukan dengan cara undian maupun langsung. BMT UGT Sidogiri memberikan hadiah kepada anggotanya dengan cara undian.

BMT UGT Sidogiri melakukan undian berhadiah dengan memberikan kupon kepada anggota yang mengikuti produk tabungan mudharabah berjangka minimal satu tahun. Setiap nominal lima juta rupiah anggota tersebut mendapatkan satu kupon berlaku untuk kelipatannya. Kupon yang diberikan kepada anggota ada empat warna yakni merah untuk anggota yang menempatkan dananya sebesar lima juta rupiah dan berkesempatan untuk mendapatkan hadiah utama yakni sepeda motor. Yang kedua adalah warna kuning bagi anggota yang menempatkan dananya hingga sepuluh juta rupiah dan berkesempatan untuk mendapatkan hadiah utama sepeda motor atau umroh. Selanjutnya yakni warna biru, warna biru diberikan kepada anggota yang menempatkan dananya hingga lima belas juta rupiah dan berkesempatan memenangkan hadiah utama yakni sepeda motor atau umroh atau mobil ayla. Warna yang keempat adalah warna hitam, bagi anggota yang menempatkan dananya hingga duapuluh juta rupiah dan berkesempatan mendapatkan hadiah utama yakni sepeda motor atau umroh atau mobil ayla atau mobil xenia. Pengundian dilakukan dengan disaksikan pengurus BMT UGT, direksi manajerial, dan perwakilan anggota BMT UGT. Berikut tabel 1 merupakan ringkasan kupon yang diberikan kepada anggota BMT UGT.

Tabel 1.

Kupon hadiah BMT UGT Sidogiri Pasuruan

\begin{tabular}{|l|l|lr|l|}
\hline No & $\begin{array}{l}\text { Warna } \\
\text { kupon }\end{array}$ & \multicolumn{2}{|l|}{ Nominal dana } & $\begin{array}{l}\text { Hadiah } \\
\text { utama }\end{array}$ \\
\hline 1 & Merah & $\begin{array}{l}\geq \\
5.000 .000,-\end{array}$ & $\begin{array}{l}\text { Sepeda } \\
\text { motor }\end{array}$ \\
\hline 2 & Kuning & $\begin{array}{l}\geq \\
10.000 .000,-\end{array}$ & $\begin{array}{l}\text { Sepeda } \\
\text { motor, } \\
\text { umroh }\end{array}$ \\
\hline 3 & Biru & $\begin{array}{l}\geq \\
15.000 .000,-\end{array}$ & $\begin{array}{l}\text { Sepeda } \\
\text { motor, } \\
\text { umroh, } \\
\text { mobil ayla }\end{array}$ \\
\hline
\end{tabular}


Nisak, et al/Jurnal Ekonomi Syariah Teori dan Terapan Vol. 4 No. 5 Mei 2017: 353-366; FATWA DSN MUI NOMOR 86/DSN-MUI/XII/2012 TENTANG HADIAH DALAM PENGHIMPUNAN DANA LEMBAGA KEUANGAN SYARIAH: IMPLEMENTASI PADA BMT UGT SIDOGIRI PASURUAN

\begin{tabular}{|l|l|ll|l|}
\hline 4 & Hitam & $\geq$ & Rp & Sepeda \\
& & $20.000 .000,-$ & motor, \\
& & & umroh, \\
& & mobil \\
& & ayla, \\
& & mobil \\
& & & xenia \\
\hline
\end{tabular}

Sumber: Hasil Analisis Peneliti (2016)

Selain hadiah utama tersebut hadiah yang diberikan oleh BMT UGT Sidogiri berupa 200 kompor gas, 40 mesin cuci, dan 20 televisi. Mekanisme pengundian selanjutnya adalah kupon tersebut dibagi menjadi 10 kotak berdasarkan kantor cabang. Semua warna kupon berhak mendapatkan hadiah doorprize yang telah disediakan, jika keluar dua kali nama tersebut maka diambil hadiah yang tertinggi dan mengambil undian lagi untuk hadiah yang gugur. Untuk kompor gas setiap kotak atau setiap kantor cabang diambil 20 kupon. Selanjutnya mesin cuci diambil 4 kupon setiap kotaknya. Televisi diambil 2 kupon setiap kotaknya. Hadiah utama yang pertama adalah sepeda motor, untuk mengundi sepeda motor setiap kotak diambil satu karena ada 10 sepeda motor yang dibagikan begitu pula dengan umroh. Selanjutnya adalah mekanisme pengambilan undian mobil ayla maupun xenia, setiap kotak diambil satu kemudian diundi lagi untuk menentukan satu orang pemenang.

\section{c. Ketentuan terkait Hadiah dalam simpanan DPK.}

Fatwa DSN MUI nomor 86/DSNMUI/XII/2012 tentang hadiah dalam penghimpunan dana lembaga keuangan syariah memberi ketentuan terkait hadiah dalam simpanan DPK lembaga keuangan syariah boleh memberikan hadiah atas simpanan nasabah dengan syarat sesuai fatwa DSN-MUI nomor 01/DSN-MUI/IV/2000 tentang giro, dan nomor 02/DSNMUI/IV/2000 tentang tabungan. Selain itu adanya larangan menjurus kepada praktik riba, dan tidak boleh menjadi kelaziman (kebiasaan, 'urf).

BMT UGT Sidogiri menjalankan program hadiah pada produk tabungan, sehingga pembahasan terbatas pada fatwa DSN MUI nomor 02/DSN-MUI/IV/2000 tentang tabungan. Fatwa DSN MUI nomor 02/DSN-MUI/IV/2000 tentang tabungan memutuskan bahwa tabungan ada dua macam yakni yang dilarang oleh syariah yaitu tabungan yang perhitungannya dengan bunga, dan tabungan yang sesuai syariah yaitu tabungan dengan prinsip mudharabah dan wadi'ah.

Ketentuan yang dikeluarkan oleh MUI tentang tabungan mudharabah meliputi:

1. LKS sebagai mudharib dan nasabah sebagai shohibul maal.

2. LKS dapat melakukan berbagai macam usaha dengan catatan sesuai dengan syariah.

3. Modal harus dinyatakan dalam jumlah tunai bukan sebagai piutang.

4. Pembagian nisbah harus jelas dan telah dijelaskan di awal kontrak. 
Nisak, et al/Jurnal Ekonomi Syariah Teori dan Terapan Vol. 4 No. 5 Mei 2017: 353-366; FATWA DSN MUI NOMOR 86/DSN-MUI/XII/2012 TENTANG HADIAH DALAM PENGHIMPUNAN DANA LEMBAGA KEUANGAN SYARIAH: IMPLEMENTASI PADA BMT UGT SIDOGIRI PASURUAN

5. LKS dilarang untuk mengurangi nisbah tanpa adanya kesepakatan dari nasabah.

Ketentuan tabungan wadi'ah yang dikeluarkan oleh MUI adalah sebagai berikut:

1. Bersifat simpanan.

2. Simpanan bisa diambil kapan saja dengan adanya kesepakatan.

3. Tidak adanya imbalan yang dipersyaratkan kecuali dalam bentuk pemberian sukarela.

BMT UGT Sidogiri menjalankan gebyar hadiah pada produk tabungan mudharabah berjangka. Tabungan mudharabah berjangka menggunakan akad mudharabah musytarakah dengan nisbah 50:50. Mudharabah musytarakah merupakan gabungan akad mudharabah dan musyarakah yang mana pengelola (mudharib atau pihak BMT) menyertakan modalnya dalam kerjasama (www.bmtugtsidogiri.co.id). Berikut penjelasan yang diberikan Pak Bahri selaku kadiv simpan pinjam.

"untuk gebyar hadiah dari awal hingga saat ini hanya ada di tabungan mudharabah berjangka. Tabungan mudharabah berjangka ini sudah jelas ya menggunakan akad mudharabah bagi hasilnya juga kami jelaskan kepada anggota seberapa besar porsi yang akan didapatkan oleh anggota dan berapa besar yang diperoleh pihak BMT. Untuk pembukaan tabungan berjangka ini harus memiliki rekening tabungan biasa terlebih dahulu, biasanya ada yang bagi hasilnya diambil tiap bulan oleh pemiliknya, yang paling sering ya kalau punya anak di pesantren sini untuk vang saku anaknya atau untuk bayar spp. Jadi potongan tabungan atas bagi hasilnya itu atas dasar persetujuan dari anggota."

Selanjutnya, larangan untuk menjadi kelaziman (kebiasaan, 'urf). 'Urf merupakan apa yang dikenal oleh manusia dan menjadi tradisi baik ucapan, perbuatan, atau pantangan dan bisa juga disebut sebagai adat (Khallaf, 1977:117). Adat terbentuk dari kebiasaan manusia menurut derajat mereka secara umum maupun tertentu. Perbedaannya dengan ijmak terbentuk dari kesepakatan mujtahid saja tidak termasuk manusia secara umum.

'Urf ada dua macam yakni adat yang benar dan adat yang rusak. Adat yang benar merupakan adat yang tidak melanggar syariat seperti adat meminta pekerjaan, atau adat membagi mas kawin menjadi dua yakni didahulukan dan diakhirkan. Sedangkan adat yang rusak adalah adat yang melanggar syariat seperti kebiasaan memakan barang riba dan akad perjudian.

Adapun adat yang rusak tidak boleh diperhatikan, karena memperhatikan adat yang rusak berarti menentang dalil syara' atau membatalkan hukum syara'. Bila manusia sudah biasa melakukan akad diantara akad-akad yang rusak, seperti akad pada barang riba atau penipuan maka kebiasaan ini tidak berarti punya pengaruh bahwa akad seperti itu diperbolehkan. Dalam hukum positif, manusia tidak diakui adanya kebiasaan 
Nisak, et al/Jurnal Ekonomi Syariah Teori dan Terapan Vol. 4 No. 5 Mei 2017: 353-366; FATWA DSN MUI NOMOR 86/DSN-MUI/XII/2012 TENTANG HADIAH DALAM PENGHIMPUNAN DANA LEMBAGA KEUANGAN SYARIAH: IMPLEMENTASI PADA BMT UGT SIDOGIRI PASURUAN

yang bertentangan dengan hukum dasar atau aturan umum.

Pakar ekonomi dan keuangan syariah bapak Suherman Rosyidi menyatakan bahwasanya 'Urf atau kelaziman yang dilarang oleh DSN MUI dalam fatwa hadiah bertujuan untuk menghindari adanya berubahnya niat seseorang dari niat menabung atau menempatkan dana beralih menjadi ingin mendapatkan hadiah. Hal ini bisa dikatakan adanya niat menuju kepada maysir atau perjudian didalamnya sebab adanya niat untuk mendapatkan sesuatu tanpa adanya kerja keras. Menurut AtTabarsi dalam Sumanta (2014) menyatakan bahwa permainan yang pemenangnya mendapatkan sejumlah vang atau barang tanpa usaha yang wajar dan dapat membuat orang jatuh ke lembah kemiskinan, permainan anakanak jika ada unsur taruhan maka termasuk dalam kategori ini.

BMT UGT Sidogiri melaksanakan gebyar hadiah setiap tahunnya semenjak tahun 2013 awal hingga sekarang. Kebiasaan ini merupakan kelaziman yang dimaksud dalam DSN MUI nomor 86/DSNMUI/XII/2012. Memberikan hadiah kepada anggota BMT UGT Sidogiri dari tahun ke tahun merupakan tindakan "urf atau kebiasaan. BMT UGT Sidogiri menganalogikan bahwa setiap tahunnya memberikan hadiah kepada anggota seperti hadiah yang diberikan guru kepada siswanya yang berprestasi. Hadiah tersebut adalah bertujuan untuk menunjang semangat dari para siswanya agar terus belajar. Hal ini sangat berbeda dengan konsep pemberian hadiah yang dilakukan oleh lembaga keuangan syariah, sebab guru memberikan hadiah kepada siswa tersebut tujuannya agar siswa semangat dalam belajar selain itu siswa tidak perlu mengeluarkan vang untuk mendapatkan hadiah tersebut. Dalam lembaga keuangan syariah memberikan hadiah secara 'Urf atau kebiasaan dilarang sebab bisa menimbulkan berubahnya niat anggota dari menabung menjadi mendapatkan keuntungan yang lebih dari tabungan tersebut. Selain itu, adanya larangan tersebut ditakutkan adanya hubungan antara lembaga keuangan syariah dengan anggota yang mengikuti gebyar hadiah tersebut terjadi sesuatu yang tidak diinginkan misalnya terjadinya kesepakatan untuk memenangkan satu pihak tersebut.

BMT UGT Sidogiri memberikan hadiah kepada anggota setiap tahunnya dengan tujuan menarik minat anggota dalam menempatkan dana di BMT UGT tersebut. Hal ini berbeda dengan ketentuan yang terdapat dalam fatwa DSN MUI no 86 tentang larangan menjadi kebiasaan dalam memberikan hadiah. Menurut fatwa DSN MUI pemberian hadiah tidak boleh menjadi kebiasan karena dalam praktiknya bisa menimbulkan berubahnya niat anggota. Hal ini terdapat dalam pernyataan ibu Yuliana sebagai berikut: 
Nisak, et al/Jurnal Ekonomi Syariah Teori dan Terapan Vol. 4 No. 5 Mei 2017: 353-366; FATWA DSN MUI NOMOR 86/DSN-MUI/XII/2012 TENTANG HADIAH DALAM PENGHIMPUNAN DANA LEMBAGA KEUANGAN SYARIAH: IMPLEMENTASI PADA BMT UGT SIDOGIRI PASURUAN

"setiap tahun memang ada gebyar hadiahnya, ini saja saya mau ikut lagi hadiahnya kan lumayan dan saya alhamdulillah nya juga ada dana."

Dari pernyataan tersebut sesuai dengan pernyataan At-Tabarsi dalam Reniati (2014) menyatakan bahwa perjudian atau maysir merupakan permainan yang pemenangnya mendapatkan sejumlah vang atau barang tanpa usaha yang wajar dan dapat membuat orang jatuh ke lembah kemiskinan, permainan anak-anak jika ada unsur taruhan maka termasuk dalam kategori ini.Dari penjelasan tersebut dapat disimpulkan bahwa:

1. BMT UGT Sidogiri menjalankan gebyar hadiah pada produk tabungan mudharabah berjangka dengan minimal satu tahun penempatan.

2. Nisbah bagi hasil yang diberikan kepada nasabah sebesar $50 \%$.

3. Kendaraan bermotor tanpa diundi bukan termasuk hadiah.

4. BMT UGT Sidogiri melakukan hybrid contract yang mengandung bai'ataini fi bai'ataini dalam produk tabungan mudharabah berjangka yang mendapatkan motor secara langsung.

5. BMT UGT Sidogiri menjalankan program hadiah setiap tahunnya dengan tujuan menarik minat anggota lama maupun baru untuk menempatkan dananya di BMT UGT Sidogiri Pasuruan.
6. BMT UGT menjalankan gebyar hadiah setiap tahun dari awal 2013 hingga saat ini. Hal ini belum sesuai dengan fatwa yang dikeluarkan oleh DSN MUI nomor 86/DSMUI/XII/2012.

\section{v. SIMPULAN}

Berdasarkan hasil penelitian yang dilakukan dapat disimpulkan bahwa proses implementasi fatwa DSN MUI nomor 86/DSN-MUI/XII/2012 tentang hadiah dalam penghimpunan dana lembaga kevangan syariah di BMT UGT Sidogiri adalah sebagai berikut:

1. Ketentuan terkait hadiah, BMT UGT Sidogiri Pasuruan memberikan hadiah kepada anggotanya berupa barang elektronik rumah tangga, dan hadiah utamanya berupa, sepeda motor, umroh, dan mobil. Selain itu, hadiah tersebut didapatkan dengan pembelian yang dilakukan menggunakan dana yang dimiliki BMT UGT pada pos BMT tanpa mengganggu dana anggota. syarat yang diajukan oleh BMT UGT kepada anggota adalah menempatkan dananya pada produk tabungan mudharabah berjangka. Hadiah yang diberikan oleh BMT UGT Sidogiri sudah sesuai dengan ketentuan terkait hadiah yang ditetapkan oleh MUI melalui DSN MUI nomor 86/DSN-MUI/XII/2012 tentang hadiah dalam penghimpunan dana lembaga kevangan syariah. 
Nisak, et al/Jurnal Ekonomi Syariah Teori dan Terapan Vol. 4 No. 5 Mei 2017: 353-366; FATWA DSN MUI NOMOR 86/DSN-MUI/XII/2012 TENTANG HADIAH DALAM PENGHIMPUNAN DANA LEMBAGA KEUANGAN SYARIAH: IMPLEMENTASI PADA BMT UGT SIDOGIRI PASURUAN

2. Ketentuan cara penentuan penerima hadiah, dalam menentukan penerima hadiah BMT UGT Sidogiri menggunakan cara undian dengan memberikan kupon kepada anggota yang mengikuti produk tabungan mudharabah berjangka minimal satu tahun penempatan. Kupon hadiah diberikan kepada anggota dengan kelipatan nominal 5 juta rupiah. Kupon yang diberikan tidak diperjual belikan. Hadiah yang diberikan kepada anggota telah dijelaskan bahkan terdapat dalam website BMT UGT Sidogiri. Undian hadiah ini tidak memungut biaya apapun dari anggota. Undian dilakukan setiap tanggal 26 Desember yang disaksikan oleh pengurus, direksi manajerial, dan perwakilan anggota. Selain itu, tidak adanya praktik risywah atau suap yang dilakukan oleh anggota terhadap pengurus dibuktikan dengan pernyataan salah satu anggota BMT yang mana pengurus tidak mau menerima apapun yang diberikan oleh anggota selama pelaksanaan hadiah. Penentuan penerima hadiah yang dilakukan BMT UGT Sidogiri Pasuruan sudah sesuai dengan fatwa DSN MUI nomor 86/DSN-MUI/XII/2012 tentang hadiah dalam penghimpunan dana lembaga keuangan syariah.
3. Ketentuan terkait hadiah dalam simpanan DPK, gebyar hadiah yang dilakukan oleh BMT UGT adalah melalui produk tabungan mudharabah berjangka. Tabungan mudharabah berjangka menggunakan gabungan akad musyarakah dan mudharabah. Hadiah di BMT UGT Sidogiri Pasuruan dilakukan setiap tahunnya, hal ini merupakan kelaziman yang dimaksud dalam fatwa DSN MUI nomor 86/DSN-MUI/XII/2012 tentang hadiah dalam penghimpunan dana lembaga keuangan syariah, sebab adanya niat yang berubah dari anggota dari menabung menjadi keinginan untuk mendapatkan sesuatu dengan tanpa adanya usaha. Ketentuan terkait hadiah dalam simpanan DPK sudah sesuai dengan fatwa DSN MUI nomor 86/DSN-MUI/XII/2012 tentang hadiah dalam penghimpunan dana lembaga keuangan syariah kecuali pada point 'Urf yang dilarang sebagaimana yang dimaksud dalam fatwa DSN MUI nomor 86/DSN-MUI/XII/2012 tentang hadiah dalam penghimpunan dana lembaga keuangan syariah.

4. Kendaraan bermotor yang didapatkan langsung tanpa diundi pada tabungan mudharabah berjangka bukan termasuk hadiah. Hal ini dikarenakan kendaraan tersebut didapatkan dengan 
Nisak, et al/Jurnal Ekonomi Syariah Teori dan Terapan Vol. 4 No. 5 Mei 2017: 353-366; FATWA DSN MUI NOMOR 86/DSN-MUI/XII/2012 TENTANG HADIAH DALAM PENGHIMPUNAN DANA LEMBAGA KEUANGAN SYARIAH: IMPLEMENTASI PADA BMT UGT SIDOGIRI PASURUAN

melakukan akad pembiayaan murabahah yang setiap bulannya pembayarannya akan dilakukan pemotongan bagi hasil yang didapatkan oleh anggota tersebut. Jika bagi hasil kurang dari pembayaran bulanan maka BMT memberikan dana tabarru' untuk menutupi, jika ada kelebihan maka menjadi hak penuh anggota. Hal ini merupakan hybrid contract yang mengandung bai'ataini fi bai'ataini atau dua akad jual beli menjadi satu akad yang saling berkaitan yang mana hal ini dilarang oleh Rasulullah SAW.

Secara keseluruhan, berdasarkan hasil analisis, BMT UGT sidogiri hampir menerapkan fatwa dsn khususnya pada fatwa DSN MUI nomor 86/DSN-MUI/XII/2012 tentang hadiah dalam penghimpunan dana lembaga keuangan syariah point larangan menjadikan kebiasaan atau 'urf dalam mengadakan program hadiah.

\section{DAFTAR PUSTAKA}

Al-Ashqalani, Al-Hafizh Ibnu Hajar. Tanpa Tahun. Bulughul Maram min Adillatil Ahkam. Terjemahan Abdul Rosyad Siddiq.2012. Jakarta : Akarmedia.

Antonio, Muhammad Syafi'i. 2001. Bank Syariah dari Teori ke Praktik. Jakarta: Gema Insani.

Azzam, Abdul AM. 2010. Fiqh Muamalah; Sistem Transaksi dalam Islam. Jakarta:Amzah

BMT Sidogiri. 2015. Tabungan MDA Berjangka Langsung dapat Mobil, (online), (http://www.bmtugtsidogiri.co.id/berita -342.html, diakses 04 Januari 2016).

Dahlan, Abdul Aziz, Et.al. 1996. Ensiklopedi Hukum Islam. Jakarta: Ichtiar Baru Van Houve.

Departemen Agama Republik Indonesia. 2005. Quran Suci: Terjemahan Dan Tafsir. Jakarta: Darul Kutubil Islamiyah.

Emzir. 2012. Metodologi Penelitian Kualitatif Analisis Data. Jakarta: Rajagrafindo Pers.

Fatwa Dewan Syariah Nasional No: 86/DSN-MUI/XII/2012 tentang Hadiah dalam Penghimpunan Dana Lembaga Kevangan Syariah.

Ferdinand, Augusty. 2006. Metode Penelitian Manajemen. Semarang: Badan Penerbit Universitas Diponegoro.

Hamidah, Lilik. 2007. Pentingnya Likuiditas Dalam Manajemen Dana Pada BMT Marsalah Mursalah Lil Ummah Pasuruan. Skripsi Tidak Diterbitkan. Malang. UIN Malang

Khallaf, Abdul Wahhab. 1977. IImu Ushul Fikih. Jakarta: Pustaka Amani.

Mardani.2012. Fiqh Ekonomi Syariah. Jakarta: Kencana Prenada Media Group.

Muttaqiyah, Matsna. 2014. "Analisis Penerapan Fatwa nomor 86/DSNMUI/XII/2012 tentang Hadiah dalam Penghimpunana Dana Lembaga Kevangan Syariah di KJKS Binama Semarang". Skripsi tidak diterbitkan. Semarang FS Universitas Islam Negri Walisongo, (online), (eprints.walisongo.ac.id, diakses 02 Oktober 2015).

Nazir, M. 2003. Metode penelitian. Jakarta: Salemba Empat.

Sayyid Sabiq. Tanpa Tahun. Fiqh asSunnah 5. Terjemahan Abdurrahim dan Masrukhin.2009. Jakarta: Cakrawala Publishing.

Soemitra, Andri. 2009. Bank dan Lembaga Keuangan Syariah. Jakarta: Kencana Prenada Media Group. 
Nisak, et al/Jurnal Ekonomi Syariah Teori dan Terapan Vol. 4 No. 5 Mei 2017: 353-366; FATWA DSN MUI NOMOR 86/DSN-MUI/XII/2012 TENTANG HADIAH DALAM PENGHIMPUNAN DANA LEMBAGA KEUANGAN SYARIAH: IMPLEMENTASI PADA BMT UGT SIDOGIRI PASURUAN

Sumanta, Reniati. 2014. "Tinjauan Hukum Islam terhadap Perjudian (Kajian perbandingan Qanun Maisir di Aceh dan Perda Perjudian di Kota Bekasi". Skripsi tidak diterbitkan. Jakarta FSH Universitas Islam Negri Syarief Hidayatullah, (online), (http://repository.uinjkt.ac.id, diakses 11 Agustus 2016).

Yin, Robert K. 1996. Studi Kasus: Desain \& Metode. Jakarta: PT RajaGrafindo 